\title{
A Common Fixed Point Theorem in G-Metric Spaces
}

\author{
S.K.Mohanta and SRIKanta Mohanta \\ Department of Mathematics, \\ West Bengal State University, \\ Barasat, 24 Pargans (North), West Bengal, Kolkata 700126, \\ email: smwbes@yahoo. in
}

\begin{abstract}
We prove a common fixed point theorem for a pair of self mappings in complete Gmetric spaces. Our result will improve and supplement some recent results in the setting of G-metric spaces.

\section{RESUMEN}

Probamos un teorema de punto fijo genérico para un par de auto-aplicaciones en espacios G-métricos completos. Nuestro resultado mejorará y complementará algunos de los resultados recientes en el marco de los espacios G-métricos.
\end{abstract}

Keywords and Phrases: G-metric space, G-Cauchy sequence, G-continuity, common fixed point. 2010 AMS Mathematics Subject Classification: 54H25, 47H10. 


\section{Introduction}

The study of metric fixed point theory has been at the centre of vigorous activity and it has a wide range of applications in applied mathematics and sciences. Over the past two decades a considerable amount of research work for the development of fixed point theory have executed by several authors. Different generalizations of the usual notion of a metric space have been proposed by Gähler [4, 5] and by Dhage [2, 3. Unfortunately, it was found that most of the results claimed by Dhage are invalid. These errors were pointed out by Mustafa and Sims in [13]. They also introduced a more appropriate concept of generalized metric space called G-metric space [9] and developed a new fixed point theory for various mappings in this new structure. Our aim in this study is to prove a common fixed point theorem in a complete G-metric space. This theorem generalizes the fixed point results of [1, 10] and [1].

\section{Preliminaries}

In this section, we present some basic definitions and results for G-metric spaces which will be needed in the sequel. Throughout this paper we denote by $\mathbb{N}$ the set of positive integers.

Definition 2.1. (see 9]) Let $X$ be a nonempty set, and let $G: X \times X \times X \rightarrow \mathbb{R}^{+}$be a function satisfying the following axioms:

$$
\begin{aligned}
& \left(G_{1}\right) G(x, y, z)=0 \text { if } x=y=z, \\
& \left(G_{2}\right) 0<G(x, x, y) \text {, for all } x, y \in X \text {, with } x \neq y, \\
& \left(G_{3}\right) G(x, x, y) \leq G(x, y, z) \text {, for all } x, y, z \in X \text {, with } z \neq y \text {, } \\
& \left(G_{4}\right) G(x, y, z)=G(x, z, y)=G(y, z, x)=\cdots \text { (symmetry in all three variables), } \\
& \left(G_{5}\right) G(x, y, z) \leq G(x, a, a)+G(a, y, z) \text {, for all } x, y, z, a \in X \text {, (rectangle inequality). }
\end{aligned}
$$

Then the function $G$ is called a generalized metric, or, more specifically a G-metric on $X$, and the pair $(X, G)$ is called a $\mathrm{G}$-metric space.

Proposition 2.1. (see [9]) Let (X, G) be a $\mathrm{G}$-metric space. Then for any $\mathrm{x}, \mathrm{y}, z$, and $\mathrm{a} \in \mathrm{X}$, it follows that

$$
\text { (1) if } G(x, y, z)=0 \text { then } x=y=z \text {, }
$$


(2) $G(x, y, z) \leq G(x, x, y)+G(x, x, z)$,

(3) $G(x, y, y) \leq 2 G(y, x, x)$,

(4) $G(x, y, z) \leq G(x, a, z)+G(a, y, z)$,

(5) $G(x, y, z) \leq \frac{2}{3}(G(x, y, a)+G(x, a, z)+G(a, y, z))$,

(6) $G(x, y, z) \leq G(x, a, a)+G(y, a, a)+G(z, a, a)$.

Definition 2.2. (see [9]) Let $(X, G)$ be a G-metric space, let $\left(x_{n}\right)$ be a sequence of points of $X$, we say that $\left(x_{n}\right)$ is G-convergent to $x$ if $\lim _{n, m \rightarrow \infty} G\left(x, x_{n}, x_{m}\right)=0$; that is, for any $\epsilon>0$, there exists $n_{0} \in \mathbb{N}$ such that $G\left(x, x_{n}, x_{m}\right)<\epsilon$, for all $n, m \geq n_{0}$. We call $x$ as the limit of the sequence $\left(x_{n}\right)$ and write $x_{n} \longrightarrow x$.

Proposition 2.2. (see 9 ) Let (X, G) be a G-metric space, then the following are equivalent.

(1) $\left(x_{n}\right)$ is $G$ - convergent to $x$.

(2) $\mathrm{G}\left(\mathrm{x}_{n}, \mathrm{x}_{\mathrm{n}}, \mathrm{x}\right) \rightarrow 0$, as $\mathrm{n} \rightarrow \infty$.

(3) $\mathrm{G}\left(x_{n}, x, x\right) \rightarrow 0$, as $n \rightarrow \infty$.

(4) $\mathrm{G}\left(x_{n}, x_{m}, x\right) \rightarrow 0$, as $n, m \rightarrow \infty$.

Definition 2.3. (see [9]) Let $(\mathrm{X}, \mathrm{G})$ be a $\mathrm{G}$-metric space, a sequence $\left(\mathrm{x}_{\mathrm{n}}\right)$ is called G-Cauchy if given $\epsilon>0$, there is $n_{0} \in \mathbb{N}$ such that $G\left(x_{n}, x_{m}, x_{l}\right)<\epsilon$, for all $n, m, l \geq n_{0}$; that is, if $\mathrm{G}\left(\mathrm{x}_{\mathrm{n}}, \mathrm{x}_{\mathrm{m}}, \mathrm{x}_{\mathrm{l}}\right) \rightarrow 0$ as $\mathrm{n}, \mathrm{m}, \mathrm{l} \rightarrow \infty$.

Definition 2.4. (see 9]) Let $(X, G)$ and $\left(X^{\prime}, G^{\prime}\right)$ be $G$-metric spaces and let $f:(X, G) \rightarrow\left(X^{\prime}, G^{\prime}\right)$ be a function, then $f$ is said to be $G$-continuous at a point $a \in X$ if given $\epsilon>0$, there exists $\delta>0$ such that $x, y \in X ; G(a, x, y)<\delta$ implies $G^{\prime}(f(a), f(x), f(y))<\epsilon$. A function $f$ is $G$-continuous on $X$ if and only if it is G-continuous at all $a \in X$.

Proposition 2.3. (see 9]) Let $(\mathrm{X}, \mathrm{G})$ and $\left(\mathrm{X}^{\prime}, \mathrm{G}^{\prime}\right)$ be $\mathrm{G}$-metric spaces, then a function $\mathrm{f}: \mathrm{X} \rightarrow \mathrm{X}^{\prime}$ is $\mathrm{G}$-continuous at a point $\mathrm{x} \in \mathrm{X}$ if and only if it is $\mathrm{G}$-sequentially continuous at $\mathrm{x}$; that is, whenever $\left(\mathrm{x}_{\mathrm{n}}\right)$ is $\mathrm{G}$-convergent to $\mathrm{x},\left(\mathrm{f}\left(\mathrm{x}_{\mathrm{n}}\right)\right)$ is $\mathrm{G}$-convergent to $\mathrm{f}(\mathrm{x})$.

Proposition 2.4. (see 9]) Let (X, G) be a $\mathrm{G}$-metric space, then the function $\mathrm{G}(\mathrm{x}, \mathrm{y}, \mathrm{z})$ is jointly continuous in all three of its variables.

Proposition 2.5. (see [9]) Every $\mathrm{G}-$-metric space $(\mathrm{X}, \mathrm{G})$ will define a metric space $\left(\mathrm{X}, \mathrm{d}_{\mathrm{G}}\right)$ by

$$
d_{G}(x, y)=G(x, y, y)+G(y, x, x), \text { for all } x, y \in X
$$


Definition 2.5. (see 9]) A G-metric space $(\mathrm{X}, \mathrm{G})$ is said to be G-complete (or a complete G-metric space) if every $\mathrm{G}$-Cauchy sequence in $(X, G)$ is $G$-convergent in $(X, G)$.

Proposition 2.6. (see 9]) A G-metric space (X, G) is $\mathrm{G}$-complete if and only if $\left(\mathrm{X}, \mathrm{d}_{\mathrm{G}}\right)$ is a complete metric space.

\section{$3 \quad$ Main Results}

Theorem 3.1. Let $(X, G)$ be a complete $G$-metric space, and let $T_{1}, T_{2}$ be mappings from $X$ into itself satisfying

$$
\max \left\{\begin{array}{c}
G\left(T_{1}(x), T_{2}\left(T_{1}(x)\right), T_{2}\left(T_{1}(x)\right)\right), \\
G\left(T_{2}(x), T_{1}\left(T_{2}(x)\right), T_{1}\left(T_{2}(x)\right)\right)
\end{array}\right\} \leq r \min \left\{\begin{array}{c}
G\left(x, T_{1}(x), T_{1}(x)\right), \\
G\left(x, T_{2}(x), T_{2}(x)\right)
\end{array}\right\}
$$

for every $x \in X$, where $0 \leq r<1$ and that

$$
\inf \left[G(x, y, y)+\min \left\{G\left(x, T_{1}(x), T_{1}(x)\right), G\left(x, T_{2}(x), T_{2}(x)\right)\right\}: x \in X\right]>0
$$

for every $y \in X$ with $y$ is not a common fixed point of $T_{1}$ and $T_{2}$.

Then $T_{1}$ and $T_{2}$ have a common fixed point in $X$.

Proof. Let $\mathrm{x}_{0} \in \mathrm{X}$ be arbitrary and define a sequence $\left(\mathrm{x}_{\mathrm{n}}\right)$ by

$$
\begin{aligned}
x_{n} & =T_{1}\left(x_{n-1}\right), \text { if } n \text { is odd } \\
& =T_{2}\left(x_{n-1}\right), \text { if } n \text { is even. }
\end{aligned}
$$

Then for any odd positive integer $n \in \mathbb{N}$, we have

$$
\begin{aligned}
G\left(x_{n}, x_{n+1}, x_{n+1}\right)= & G\left(T_{1}\left(x_{n-1}\right), T_{2}\left(x_{n}\right), T_{2}\left(x_{n}\right)\right) \\
= & G\left(T_{1}\left(x_{n-1}\right), T_{2}\left(T_{1}\left(x_{n-1}\right)\right), T_{2}\left(T_{1}\left(x_{n-1}\right)\right)\right) \\
\leq & \max \left\{\begin{array}{l}
G\left(T_{1}\left(x_{n-1}\right), T_{2}\left(T_{1}\left(x_{n-1}\right)\right), T_{2}\left(T_{1}\left(x_{n-1}\right)\right)\right), \\
G\left(T_{2}\left(x_{n-1}\right), T_{1}\left(T_{2}\left(x_{n-1}\right)\right), T_{1}\left(T_{2}\left(x_{n-1}\right)\right)\right)
\end{array}\right\} \\
\leq & \operatorname{rmin}\left\{\begin{array}{l}
G\left(x_{n-1}, T_{1}\left(x_{n-1}\right), T_{1}\left(x_{n-1}\right)\right), \\
G\left(x_{n-1}, T_{2}\left(x_{n-1}\right), T_{2}\left(x_{n-1}\right)\right)
\end{array}\right\}, \text { by (3.1) } \\
\leq & r G\left(x_{n-1}, T_{1}\left(x_{n-1}\right), T_{1}\left(x_{n-1}\right)\right) \\
= & r G\left(x_{n-1}, x_{n}, x_{n}\right) .
\end{aligned}
$$


If $n$ is even, then by (3.1), we have

$$
\begin{aligned}
G\left(x_{n}, x_{n+1}, x_{n+1}\right) & =G\left(T_{2}\left(x_{n-1}\right), T_{1}\left(x_{n}\right), T_{1}\left(x_{n}\right)\right) \\
& =G\left(T_{2}\left(x_{n-1}\right), T_{1}\left(T_{2}\left(x_{n-1}\right)\right), T_{1}\left(T_{2}\left(x_{n-1}\right)\right)\right) \\
\leq & \max \left\{\begin{array}{r}
G\left(T_{1}\left(x_{n-1}\right), T_{2}\left(T_{1}\left(x_{n-1}\right)\right), T_{2}\left(T_{1}\left(x_{n-1}\right)\right)\right), \\
G\left(T_{2}\left(x_{n-1}\right), T_{1}\left(T_{2}\left(x_{n-1}\right)\right), T_{1}\left(T_{2}\left(x_{n-1}\right)\right)\right)
\end{array}\right\} \\
\leq & \operatorname{rmin}\left\{\begin{array}{c}
G\left(x_{n-1}, T_{1}\left(x_{n-1}\right), T_{1}\left(x_{n-1}\right)\right), \\
G\left(x_{n-1}, T_{2}\left(x_{n-1}\right), T_{2}\left(x_{n-1}\right)\right)
\end{array}\right\} \\
\leq & r G\left(x_{n-1}, T_{2}\left(x_{n-1}\right), T_{2}\left(x_{n-1}\right)\right) \\
= & r G\left(x_{n-1}, x_{n}, x_{n}\right) .
\end{aligned}
$$

Thus for any positive integer $n$, it must be the case that

$$
G\left(x_{n}, x_{n+1}, x_{n+1}\right) \leq r G\left(x_{n-1}, x_{n}, x_{n}\right) .
$$

By repeated application of (3.2), we obtain

$$
G\left(x_{n}, x_{n+1}, x_{n+1}\right) \leq r^{n} G\left(x_{0}, x_{1}, x_{1}\right) \text {. }
$$

Then, for all $n, m \in \mathbb{N}, n<m$, we have by repeated use of the rectangle inequality and (3.3) that

$$
\begin{aligned}
\mathrm{G}\left(x_{n}, x_{m}, x_{m}\right) \leq & G\left(x_{n}, x_{n+1}, x_{n+1}\right)+G\left(x_{n+1}, x_{n+2}, x_{n+2}\right) \\
& +G\left(x_{n+2}, x_{n+3}, x_{n+3}\right)+\cdots+G\left(x_{m-1}, x_{m}, x_{m}\right) \\
\leq & \left(r^{n}+r^{n+1}+\cdots+r^{m-1}\right) G\left(x_{0}, x_{1}, x_{1}\right) \\
\leq & \frac{r^{n}}{1-r} G\left(x_{0}, x_{1}, x_{1}\right) .
\end{aligned}
$$

Then, $\lim G\left(x_{n}, x_{m}, x_{m}\right)=0$, as $n, m \rightarrow \infty$, since $\lim \frac{r^{n}}{1-r} G\left(x_{0}, x_{1}, x_{1}\right)=0$, as $n, m \rightarrow \infty$. For $n, m, l \in \mathbb{N},\left(G_{5}\right)$ implies that

$$
\mathrm{G}\left(x_{n}, x_{m}, x_{l}\right) \leq \mathrm{G}\left(x_{n}, x_{m}, x_{m}\right)+G\left(x_{l}, x_{m}, x_{m}\right),
$$

taking limit as $\mathrm{n}, \mathrm{m}, \mathrm{l} \rightarrow \infty$, we get $\mathrm{G}\left(\mathrm{x}_{\mathrm{n}}, \mathrm{x}_{\mathrm{m}}, \mathrm{x}_{\mathrm{l}}\right) \rightarrow 0$. So $\left(\mathrm{x}_{\mathrm{n}}\right)$ is a G-Cauchy sequence. By completeness of $(X, G)$, there exists $\mathfrak{u} \in X$ such that $\left(x_{\mathfrak{n}}\right)$ is $\mathrm{G}$-convergent to $\mathfrak{u}$.

Let $n \in \mathbb{N}$ be fixed. Then, since $\left(x_{m}\right) G$-converges to $u$ and $G$ is continuous on its variables, we have

$$
G\left(x_{n}, u, u\right)=\lim _{m \rightarrow \infty} G\left(x_{n}, x_{m}, x_{m}\right) \leq \frac{r^{n}}{1-r} G\left(x_{0}, x_{1}, x_{1}\right)
$$


Assume that $u$ is not a common fixed point of $T_{1}$ and $T_{2}$. Then, by hypothesis, we have

$$
\begin{aligned}
0 & <\inf \left[G(x, u, u)+\min \left\{G\left(x, T_{1}(x), T_{1}(x)\right), G\left(x, T_{2}(x), T_{2}(x)\right)\right\}: x \in X\right] \\
& \leq \inf \left[G\left(x_{n}, u, u\right)+\min \left\{G\left(x_{n}, T_{1}\left(x_{n}\right), T_{1}\left(x_{n}\right)\right), G\left(x_{n}, T_{2}\left(x_{n}\right), T_{2}\left(x_{n}\right)\right)\right\}: n \in \mathbb{N}\right] \\
& \leq \inf \left[\frac{r^{n}}{1-r} G\left(x_{0}, x_{1}, x_{1}\right)+G\left(x_{n}, x_{n+1}, x_{n+1}\right): n \in \mathbb{N}\right] \\
& \leq \inf \left[\frac{r^{n}}{1-r} G\left(x_{0}, x_{1}, x_{1}\right)+r^{n} G\left(x_{0}, x_{1}, x_{1}\right): n \in \mathbb{N}\right] \\
& =0
\end{aligned}
$$

which is a contradiction. Therefore, $u$ is a common fixed point of $T_{1}$ and $T_{2}$.

Theorem 3.2. Let $(X, G)$ be a complete $G$-metric space, and let $T_{1}, T_{2}$ be mappings from $X$ into itself satisfying

$$
\max \left\{\begin{array}{c}
G\left(T_{1}(x), T_{1}(x), T_{2}\left(T_{1}(x)\right)\right), \\
G\left(T_{2}(x), T_{2}(x), T_{1}\left(T_{2}(x)\right)\right)
\end{array}\right\} \leq r \min \left\{\begin{array}{c}
G\left(x, x, T_{1}(x)\right), \\
G\left(x, x, T_{2}(x)\right)
\end{array}\right\}
$$

for every $x \in X$, where $0 \leq r<1$ and that

$$
\inf \left[G(x, x, y)+\min \left\{G\left(x, x, T_{1}(x)\right), G\left(x, x, T_{2}(x)\right)\right\}: x \in X\right]>0
$$

for every $y \in X$ with $y$ is not a common fixed point of $T_{1}$ and $T_{2}$.

Then $T_{1}$ and $T_{2}$ have a common fixed point in $X$.

Proof. Let $x_{0} \in X$ be arbitrary and define a sequence $\left(x_{n}\right)$ by

$$
\begin{aligned}
x_{n} & =T_{1}\left(x_{n-1}\right), \text { if } n \text { is odd } \\
& =T_{2}\left(x_{n-1}\right), \text { if } n \text { is even. }
\end{aligned}
$$

Then by the argument similar to that used in Theorem 3.1. we have for any positive integer $n$,

$$
G\left(x_{n}, x_{n}, x_{n+1}\right) \leq r^{n} G\left(x_{0}, x_{0}, x_{1}\right)
$$

Then, for all $n, m \in \mathbb{N}, n<m$, we have by repeated use of the rectangle inequality and (3.5) that

$$
\begin{aligned}
\mathrm{G}\left(x_{\mathrm{m}}, x_{\mathrm{n}}, x_{\mathrm{n}}\right) \leq & \mathrm{G}\left(x_{\mathrm{m}}, x_{\mathrm{m}-1}, x_{\mathrm{m}-1}\right)+\mathrm{G}\left(x_{\mathrm{m}-1}, x_{\mathrm{m}-2}, x_{\mathrm{m}-2}\right) \\
& +\mathrm{G}\left(x_{\mathrm{m}-2}, x_{\mathrm{m}-3}, x_{\mathrm{m}-3}\right)+\cdots+\mathrm{G}\left(x_{\mathrm{n}+1}, x_{\mathrm{n}}, x_{\mathrm{n}}\right) \\
\leq & \left(\mathrm{r}^{\mathrm{n}}+\mathrm{r}^{\mathrm{n}+1}+\cdots+\mathrm{r}^{\mathrm{m}-1}\right) \mathrm{G}\left(x_{0}, x_{0}, x_{1}\right) \\
\leq & \frac{r^{n}}{1-r} \mathrm{G}\left(x_{0}, x_{0}, x_{1}\right) .
\end{aligned}
$$


Thus $\left(x_{\mathfrak{n}}\right)$ becomes a G-Cauchy sequence. By completeness of $(X, G)$, there exists $u \in X$ such that $\left(x_{n}\right)$ is G-convergent to $u$.

Let $n \in \mathbb{N}$ be fixed. Then since $\left(x_{m}\right)$ G-converges to $u$ and $G$ is continuous on its variables, we have

$$
G\left(x_{n}, x_{n}, u\right)=\lim _{m \rightarrow \infty} G\left(x_{n}, x_{n}, x_{m}\right) \leq \frac{r^{n}}{1-r} G\left(x_{0}, x_{0}, x_{1}\right) .
$$

The argument similar to that used in the proof of Theorem 3.1 establishes that $u$ is a common fixed point of $T_{1}$ and $T_{2}$.

Combining Theorem 3.1 and Theorem 3.2, we state the following Theorem:

Theorem 3.3. Let $(X, G)$ be a complete $G$-metric space, and let $T_{1}, T_{2}$ be mappings from $X$ into itself satisfying one of the following conditions:

$$
\max \left\{\begin{array}{c}
G\left(T_{1}(x), T_{2}\left(T_{1}(x)\right), T_{2}\left(T_{1}(x)\right)\right), \\
G\left(T_{2}(x), T_{1}\left(T_{2}(x)\right), T_{1}\left(T_{2}(x)\right)\right)
\end{array}\right\} \leq r \min \left\{\begin{array}{c}
G\left(x, T_{1}(x), T_{1}(x)\right), \\
G\left(x, T_{2}(x), T_{2}(x)\right)
\end{array}\right\}
$$

for every $x \in X$, where $0 \leq r<1$ and that

$$
\inf \left[G(x, y, y)+\min \left\{G\left(x, T_{1}(x), T_{1}(x)\right), G\left(x, T_{2}(x), T_{2}(x)\right)\right\}: x \in X\right]>0
$$

for every $y \in X$ with $y$ is not a common fixed point of $T_{1}$ and $T_{2}$.

or

$$
\max \left\{\begin{array}{c}
G\left(T_{1}(x), T_{1}(x), T_{2}\left(T_{1}(x)\right)\right), \\
G\left(T_{2}(x), T_{2}(x), T_{1}\left(T_{2}(x)\right)\right)
\end{array}\right\} \leq r \min \left\{\begin{array}{c}
G\left(x, x, T_{1}(x)\right), \\
G\left(x, x, T_{2}(x)\right)
\end{array}\right\}
$$

for every $x \in X$, where $0 \leq r<1$ and that

$$
\inf \left[G(x, x, y)+\min \left\{G\left(x, x, T_{1}(x)\right), G\left(x, x, T_{2}(x)\right)\right\}: x \in X\right]>0
$$

for every $y \in X$ with $y$ is not a common fixed point of $T_{1}$ and $T_{2}$.

Then $T_{1}$ and $T_{2}$ have a common fixed point in $X$.

As an application of Theorem 3.3, we have the following Corollary. 
Corollary 1. Let $(\mathrm{X}, \mathrm{G})$ be a complete $\mathrm{G}$-metric space, and let $\mathrm{T}: \mathrm{X} \rightarrow \mathrm{X}$ be a mapping satisfying one of the following conditions:

$$
G\left(T(x), T^{2}(x), T^{2}(x)\right) \leq r G(x, T(x), T(x))
$$

for every $\mathrm{x} \in \mathrm{X}$, where $0 \leq \mathrm{r}<1$ and that

$$
\inf [G(x, y, y)+G(x, T(x), T(x)): x \in X]>0
$$

for every $\mathrm{y} \in \mathrm{X}$ with $\mathrm{y} \neq \mathrm{T}(\mathrm{y})$.

$$
\begin{gathered}
\text { or } \\
G\left(T(x), T(x), T^{2}(x)\right) \leq r G(x, x, T(x))
\end{gathered}
$$

for every $\mathrm{x} \in \mathrm{X}$, where $0 \leq \mathrm{r}<1$ and that

$$
\inf [G(x, x, y)+G(x, x, T(x)): x \in X]>0
$$

for every $\mathrm{y} \in \mathrm{X}$ with $\mathrm{y} \neq \mathrm{T}(\mathrm{y})$.

Then $\mathrm{T}$ has a fixed point in $\mathrm{X}$.

Proof. Take $\mathrm{T}_{1}=\mathrm{T}_{2}=\mathrm{T}$ in Theorem 3.3 .

We now supplement Corollary 1 by examination of condition (3.6) (or, (3.8)) and condition (3.7) (or, (3.9) ) in respect of their independence. In fact, we furnish Example 3.1 and Example 3.2 below to show that these two conditions are independent in the sense that Corollary 1 shall fall through by dropping one in favour of the other.

Example 3.1. Let $X=\{0\} \cup\left\{\frac{1}{2^{n}}: n \geq 1\right\}$. Define $G: X \times X \times X \rightarrow \mathbb{R}^{+}$by

$$
\mathrm{G}(x, y, z)=\frac{1}{4}|x-y|+\frac{1}{4}|y-z|+\frac{1}{4}|z-x|, \text { for all } x, y, z \in X .
$$

Then $(X, G)$ is a complete $G$-metric space.

Define $T: X \rightarrow X$ by $T(0)=\frac{1}{2}$ and $T\left(\frac{1}{2^{n}}\right)=\frac{1}{2^{n+T}}$ for $n \geq 1$. Clearly, $T$ has got no fixed point in $X$. Also, it is easy to check that

$$
G\left(T(x), T^{2}(x), T^{2}(x)\right)=\frac{1}{2} G(x, T(x), T(x))
$$

for every $x \in X$.

Thus, condition (3.6) in Corollary 1 is satisfied. However, $\mathrm{T}(\mathrm{y}) \neq \mathrm{y}$ for all $\mathrm{y} \in \mathrm{X}$ and so

$$
\inf \{G(x, y, y)+G(x, T(x), T(x)): x, y \in X \text { with } y \neq T(y)\}
$$




$$
\begin{aligned}
& =\quad \inf \{G(x, y, y)+G(x, T(x), T(x)): x, y \in X\} \\
& =\inf \left\{\frac{1}{2}|x-y|+\frac{1}{2}|x-T(x)|: x, y \in X\right\} \\
& =0 .
\end{aligned}
$$

Thus condition (3.7) in Corollary 1 does not hold.

Similarly, we can verify that condition (3.8) in Corollary 1 is also satisfied but condition (3.9) fails. Clearly, the conclusion of Corollary 1 is not valid.

Example 3.2. Take $X=\{0,1\} \cup[2, \infty)$. Define $G: X \times X \times X \rightarrow \mathbb{R}^{+}$by

$$
\mathrm{G}(x, y, z)=\frac{1}{4}|x-y|+\frac{1}{4}|y-z|+\frac{1}{4}|z-x|, \text { for all } x, y, z \in X
$$

Then $(X, G)$ is a complete $\mathrm{G}$-metric space.

Define $T: X \rightarrow X$ by

$$
\begin{aligned}
T(x) & =0, \text { for } x \neq 0 \\
& =1, \text { for } x=0 .
\end{aligned}
$$

Clearly, $T$ possesses no fixed point in $X$.

Since $T(y) \neq y$ for all $y \in X$, we have

$$
\begin{aligned}
\inf \{G(x, y, y)+G(x, T(x), T(x)): x, y \in X \text { with } y \neq T(y)\} \\
\quad=\inf \{G(x, y, y)+G(x, T(x), T(x)): x, y \in X\} \\
\quad=\inf \left\{\frac{1}{2}|x-y|+\frac{1}{2}|x-T(x)|: x, y \in X\right\} \\
>0 .
\end{aligned}
$$

Thus condition (3.7) in Corollary 1 is satisfied.

However, for $x=0$, we have

$$
G\left(T(x), T^{2}(x), T^{2}(x)\right)=\frac{1}{2}\left|T(x)-T^{2}(x)\right|=\frac{1}{2}>r G(x, T(x), T(x))
$$

for any $r \in[0,1)$.

This shows that condition (3.6) in Corollary 1 does not hold.

Similarly, we can check that condition (3.9) in Corollary 1 is also satisfied but condition (3.8) fails. Obviously, Corollary 1 is invalid in this case.

As an application of Corollary 1, we have the following results. 
Corollary 2. Let $(\mathrm{X}, \mathrm{G})$ be a complete $\mathrm{G}$-metric space, and let $\mathrm{T}: \mathrm{X} \rightarrow \mathrm{X}$ be a $\mathrm{G}$-continuous mapping satisfying one of the following conditions:

$$
G\left(T(x), T^{2}(x), T^{2}(x)\right) \leq r G(x, T(x), T(x))
$$

or

$$
G\left(T(x), T(x), T^{2}(x)\right) \leq r G(x, x, T(x))
$$

for every $\mathrm{x} \in \mathrm{X}$, where $0 \leq \mathrm{r}<1$. Then $\mathrm{T}$ has a fixed point in $\mathrm{X}$.

Proof. Suppose that T satisfies condition (3.10) for every $x \in X$. Assume that there exists $y \in X$ with $y \neq T(y)$ and

$$
\inf [G(x, y, y)+G(x, T(x), T(x)): x \in X]=0 .
$$

Then there exists a sequence $\left(x_{n}\right)$ in $X$ such that

$$
\lim _{n \rightarrow \infty}\left\{G\left(x_{n}, y, y\right)+G\left(x_{n}, T\left(x_{n}\right), T\left(x_{n}\right)\right)\right\}=0,
$$

which implies that,

$$
\mathrm{G}\left(x_{n}, y, y\right) \rightarrow 0 \text { and } \mathrm{G}\left(x_{n}, \mathrm{~T}\left(x_{n}\right), T\left(x_{n}\right)\right) \rightarrow 0 \text { as } n \rightarrow \infty .
$$

So, by Proposition 2.2, the sequence $\left(x_{n}\right)$ is G-convergent to $y$.

But by $\left(\mathrm{G}_{5}\right)$, we have

$$
\begin{aligned}
\mathrm{G}\left(\mathrm{T}\left(x_{n}\right), y, y\right) & \leq \mathrm{G}\left(\mathrm{T}\left(x_{n}\right), x_{n}, x_{n}\right)+\mathrm{G}\left(x_{n}, y, y\right) \\
& \leq 2 \mathrm{G}\left(x_{n}, T\left(x_{n}\right), T\left(x_{n}\right)\right)+G\left(x_{n}, y, y\right) \\
& \rightarrow 0 \text { as } n \rightarrow \infty .
\end{aligned}
$$

Again, by Proposition 2.2 the sequence $\left(\mathrm{T}\left(\mathrm{x}_{\mathrm{n}}\right)\right)$ is G-convergent to $\mathrm{y}$. So G-continuity of $\mathrm{T}$ implies that, $\left(T^{2}\left(x_{n}\right)\right)$ G-converges to $T(y)$.

Then by use of the rectangle inequality and (3.10) that

$$
\begin{aligned}
G\left(x_{n}, T^{2}\left(x_{n}\right), T^{2}\left(x_{n}\right)\right) & \leq G\left(x_{n}, T\left(x_{n}\right), T\left(x_{n}\right)\right)+G\left(T\left(x_{n}\right), T^{2}\left(x_{n}\right), T^{2}\left(x_{n}\right)\right) \\
& \leq G\left(x_{n}, T\left(x_{n}\right), T\left(x_{n}\right)\right)+r G\left(x_{n}, T\left(x_{n}\right), T\left(x_{n}\right)\right) .
\end{aligned}
$$

Taking the limit as $n \rightarrow \infty$, and using the fact that the function $\mathrm{G}$ is continuous on its variables, we have

$$
\begin{aligned}
G(y, T(y), T(y)) & \leq G(y, y, y)+r G(y, y, y) \\
& =0
\end{aligned}
$$


which implies that, $y=T(y)$. This is a contradiction.

Hence, if $\mathrm{y} \neq \mathrm{T}(\mathrm{y})$, then

$$
\inf [G(x, y, y)+G(x, T(x), T(x)): x \in X]>0 .
$$

If $T$ satisfies condition (3.11), then using the same methods as above one can prove that

$$
\inf [G(x, x, y)+G(x, x, T(x)): x \in X]>0 .
$$

So, using Corollary 1, we have the desired result.

The following Corollary is a generalization of the result [[1], Theorem 2.1].

Corollary 3. Let $(\mathrm{X}, \mathrm{G})$ be a complete $\mathrm{G}-$ metric space, and let $\mathrm{T}: \mathrm{X} \rightarrow \mathrm{X}$ be a mapping satisfying one of the following conditions:

$$
\begin{aligned}
& G(T(x), T(y), T(z)) \leq k \max \left\{\begin{array}{l}
G(x, y, z), G(x, T(x), T(x)), \\
G(y, T(y), T(y)), G(z, T(z), T(z)), \\
\frac{G(x, T(y), T(y))+G(z, T(x), T(x))}{2}, \\
\frac{G(x, T(y), T(y))+G(y, T(x), T(x))}{2}, \\
\frac{G(y, T(z), T(z))+G(z, T(y), T(y))}{2}, \\
\frac{G(x, T(z), T(z))+G(z, T(x), T(x))}{2}
\end{array}\right\} \\
& \text { or } \\
& G(T(x), T(y), T(z)) \leq k \max \left\{\begin{array}{l}
G(x, y, z), G(x, x, T(x)), \\
G(y, y, T(y)), G(z, z, T(z)), \\
\frac{G(x, x, T(y))+G(z, z, T(x))}{2}, \\
\frac{G(x, x, T(y))+G(y, y, T(x))}{2}, \\
\frac{G(y, y, T(z))+G(z, z, T(y))}{2}, \\
\frac{G(x, x, T(z))+G(z, z, T(x))}{2}
\end{array}\right\}
\end{aligned}
$$


for all $\mathrm{x}, \mathrm{y}, \mathrm{z} \in \mathrm{X}$, where $\mathrm{O} \leq \mathrm{k}<1$. Then $\mathrm{T}$ has a unique fixed point (say $\mathrm{u}$ ) in $\mathrm{X}$ and $\mathrm{T}$ is $\mathrm{G}$-continuous at $\mathrm{u}$.

Proof. Suppose that $T$ satisfies condition (3.12) for all $x, y, z \in X$. Then replacing $y$ and $z$ by $T(x)$, we obtain from (3.12) and using $\left(\mathrm{G}_{5}\right)$ that

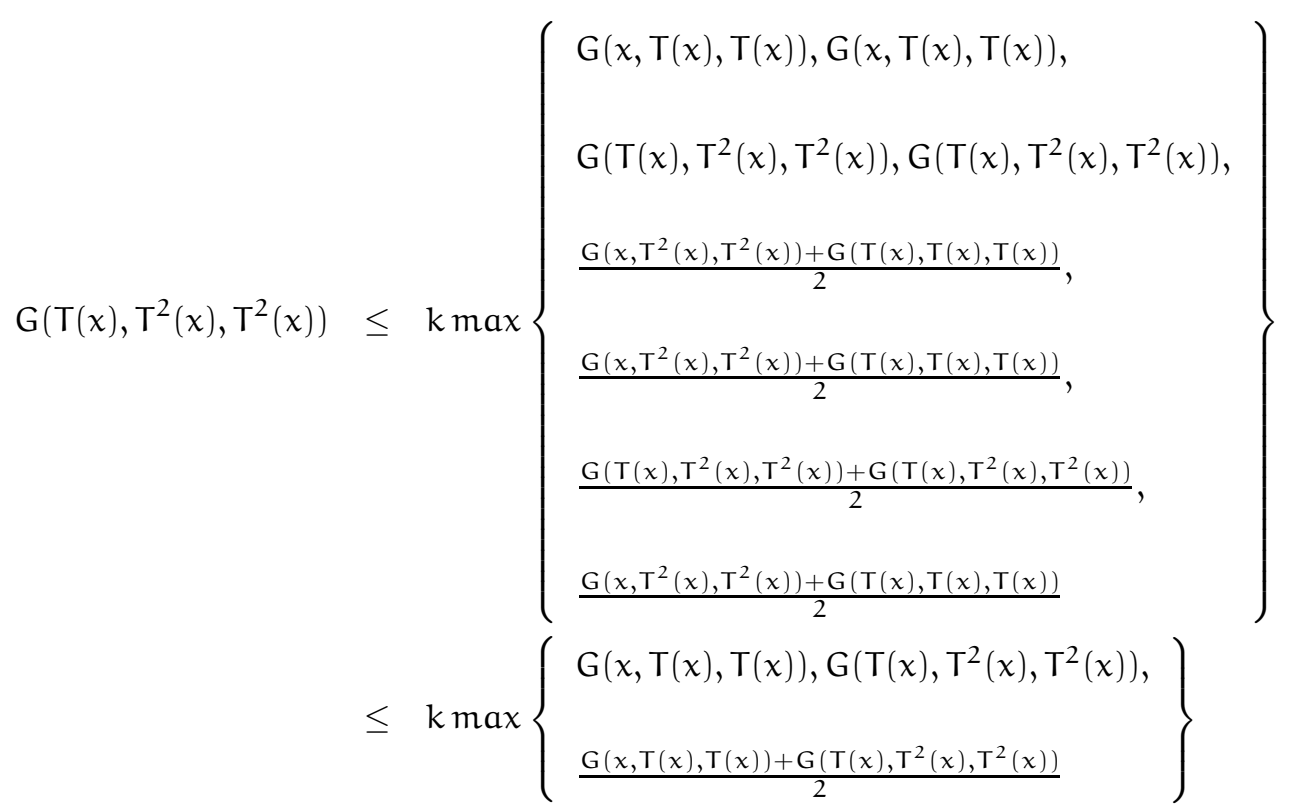

Without loss of generality we may assume that $T(x) \neq T^{2}(x)$. For, otherwise, $T$ has a fixed point. So, (3.14) leads to the following cases,

(1) $G\left(T(x), T^{2}(x), T^{2}(x)\right) \leq k \frac{G(x, T(x), T(x))+G\left(T(x), T^{2}(x), T^{2}(x)\right)}{2}$,

(2) $G\left(T(x), T^{2}(x), T^{2}(x)\right) \leq k G(x, T(x), T(x))$.

In the first case, we have

$$
G\left(T(x), T^{2}(x), T^{2}(x)\right) \leq \frac{k}{2-k} G(x, T(x), T(x)) .
$$

Put $r=\frac{k}{2-k}$. Then $0 \leq r<1$.

Thus, in each case we must have

$$
G\left(T(x), T^{2}(x), T^{2}(x)\right) \leq r G(x, T(x), T(x))
$$

for every $x \in X$, where $0 \leq r<1$.

Assume that there exists $y \in X$ with $y \neq T(y)$ and

$$
\inf [G(x, y, y)+G(x, T(x), T(x)): x \in X]=0 .
$$


Proceeding exactly the same way as in the proof of Corollary 2, there exists a sequence $\left(x_{n}\right)$ in $X$ such that $\left(x_{n}\right)$ is G-convergent to $y$ and $\left(T\left(x_{n}\right)\right)$ is G-convergent to $y$.

Now applying (3.12), we have

$$
G\left(T\left(x_{n}\right), T(y), T(y)\right) \leq k \max \left\{\begin{array}{c}
G\left(x_{n}, y, y\right), G\left(x_{n}, T\left(x_{n}\right), T\left(x_{n}\right)\right), \\
G(y, T(y), T(y)), G(y, T(y), T(y)), \\
\frac{G\left(x_{n}, T(y), T(y)\right)+G\left(y, T\left(x_{n}\right), T\left(x_{n}\right)\right)}{2}, \\
\frac{G\left(x_{n}, T(y), T(y)\right)+G\left(y, T\left(x_{n}\right), T\left(x_{n}\right)\right)}{2}, \\
\frac{G(y, T(y), T(y))+G(y, T(y), T(y))}{2}, \\
\frac{G\left(x_{n}, T(y), T(y)\right)+G\left(y, T\left(x_{n}\right), T\left(x_{n}\right)\right)}{2}
\end{array}\right\} .
$$

Taking the limit as $\mathrm{n} \rightarrow \infty$, and using the fact that the function $\mathrm{G}$ is continuous on its variables, we obtain

$$
G(y, T(y), T(y)) \leq k G(y, T(y), T(y))
$$

which is a contradiction.

Hence, if $y \neq T(y)$, then

$$
\inf [G(x, y, y)+G(x, T(x), T(x)): x \in X]>0 .
$$

Now Corollary 1 applies to obtain a fixed point (say u) of $\mathrm{T}$.

The proof using (3.13) is similar. Uniqueness of $u$ and $\mathrm{G}$-continuity of $\mathrm{T}$ at $\boldsymbol{u}$ may be verified in the usual way by using any one of condition (3.12) and condition (3.13) that $\mathrm{T}$ satisfies.

Remark 1. We see that special cases of Corollary 3 are Theorem 2.1 of [1], Theorem 2.1 of [1] and Theorems 2.1, and 2.4 of [10].

The following Corollary is the result [[1, Theorem 2.2].

Corollary 4. Let $(\mathrm{X}, \mathrm{G})$ be a complete $\mathrm{G}$-metric space, and let $\mathrm{T}: \mathrm{X} \rightarrow \mathrm{X}$ be a mapping satisfying one of the following conditions:

$$
G(T(x), T(y), T(z)) \leq k \max \left\{\begin{array}{l}
G(x, y, z), G(x, T(x), T(x)), \\
G(y, T(y), T(y)), G(x, T(y), T(y)), \\
G(y, T(x), T(x)), G(z, T(z), T(z))
\end{array}\right\}
$$




$$
G(T(x), T(y), T(z)) \leq k \max \left\{\begin{array}{l}
G(x, y, z), G(x, x, T(x)), \\
G(y, y, T(y)), G(x, x, T(y)), \\
G(y, y, T(x)), G(z, z, T(z))
\end{array}\right\}
$$

for all $\mathrm{x}, \mathrm{y}, \mathrm{z} \in \mathrm{X}$, where $\mathrm{O} \leq \mathrm{k}<1$. Then $\mathrm{T}$ has a unique fixed point (say $\mathrm{u}$ ) in $\mathrm{X}$ and $\mathrm{T}$ is $\mathrm{G}$-continuous at $\mathrm{u}$.

Proof. Suppose that T satisfies condition (3.15) for all $x, y, z \in X$. Then replacing $z$ by $x ; y$ and $x$ by $T(x)$ in (3.15), we have

$$
\begin{aligned}
G\left(T^{2}(x), T^{2}(x), T(x)\right) \leq k \max \left\{\begin{array}{l}
G(T(x), T(x), x), G\left(T(x), T^{2}(x), T^{2}(x)\right), \\
G\left(T(x), T^{2}(x), T^{2}(x)\right), G\left(T(x), T^{2}(x), T^{2}(x)\right), \\
G\left(T(x), T^{2}(x), T^{2}(x)\right), G(x, T(x), T(x))
\end{array}\right\} \\
\leq k \max \left\{G(x, T(x), T(x)), G\left(T(x), T^{2}(x), T^{2}(x)\right)\right\} .
\end{aligned}
$$

Without loss of generality we may assume that $T(x) \neq T^{2}(x)$. For, otherwise, $T$ has a fixed point.

So, it must be the case that,

$$
G\left(T(x), T^{2}(x), T^{2}(x)\right) \leq k G(x, T(x), T(x))
$$

for every $x \in X$, where $0 \leq k<1$.

By the same argument used in the proof of Corollary 3 , we see that if $y \neq T(y)$, then

$$
\inf [G(x, y, y)+G(x, T(x), T(x)): x \in X]>0 .
$$

Now Corollary 1 applies to obtain a fixed point (say u) of T.

The proof using (3.16) is similar. Uniqueness of $u$ and $G$-continuity of $T$ at $u$ are obtained by the same argument used in Corollary 3

The following Corollary is the result [[11], Theorem 2.9].

Corollary 5. Let $(\mathrm{X}, \mathrm{G})$ be a complete $\mathrm{G}$-metric space, and let $\mathrm{T}: \mathrm{X} \rightarrow \mathrm{X}$ be a mapping satisfying one of the following conditions:

$$
G(T(x), T(y), T(y)) \leq a\{G(x, T(y), T(y))+G(y, T(x), T(x))\}
$$




$$
\mathrm{G}(\mathrm{T}(\mathrm{x}), \mathrm{T}(\mathrm{y}), \mathrm{T}(\mathrm{y})) \leq \mathrm{a}\{\mathrm{G}(\mathrm{x}, \mathrm{x}, \mathrm{T}(\mathrm{y}))+\mathrm{G}(\mathrm{y}, \mathrm{y}, \mathrm{T}(\mathrm{x}))\}
$$

for all $\mathrm{x}, \mathrm{y} \in \mathrm{X}$, where $\mathrm{O} \leq \mathrm{a}<\frac{1}{2}$. Then $\mathrm{T}$ has a unique fixed point (say $\mathrm{u}$ ) in $\mathrm{X}$ and $\mathrm{T}$ is $\mathrm{G}$-continuous at $\mathrm{u}$.

Proof. Suppose that $T$ satisfies condition (3.17) for all $x, y \in X$. Then replacing y by $T(x)$ in (3.17), we have

$$
\begin{aligned}
G\left(T(x), T^{2}(x), T^{2}(x)\right) & \leq a\left\{G\left(x, T^{2}(x), T^{2}(x)\right)+G(T(x), T(x), T(x))\right\} \\
& \leq a\left\{G(x, T(x), T(x))+G\left(T(x), T^{2}(x), T^{2}(x)\right)\right\}, \text { by }\left(G_{5}\right) .
\end{aligned}
$$

So, it must be the case that,

$$
G\left(T(x), T^{2}(x), T^{2}(x)\right) \leq \frac{a}{1-a} G(x, T(x), T(x)) .
$$

Put $r=\frac{a}{1-a}$. Then $0 \leq r<1$ since $0 \leq a<\frac{1}{2}$.

Thus,

$$
G\left(T(x), T^{2}(x), T^{2}(x)\right) \leq r G(x, T(x), T(x)) .
$$

for every $x \in X$, where $0 \leq r<1$.

Assume that there exists $y \in X$ with $y \neq T(y)$ and

$$
\inf [G(x, y, y)+G(x, T(x), T(x)): x \in X]=0 .
$$

As in the proof of Corollary 2, there exists a sequence $\left(x_{n}\right)$ in $X$ such that $\left(x_{n}\right)$ is G-convergent to $y$ and $\left(T\left(x_{n}\right)\right)$ is G-convergent to $y$.

Now using (3.17), we have

$$
G\left(T\left(x_{n}\right), T(y), T(y)\right) \leq a\left\{G\left(x_{n}, T(y), T(y)\right)+G\left(y, T\left(x_{n}\right), T\left(x_{n}\right)\right)\right\} .
$$

Taking the limit as $\mathrm{n} \rightarrow \infty$, and using the fact that the function $\mathrm{G}$ is continuous on its variables, we have

$$
\begin{aligned}
G(y, T(y), T(y)) & \leq a\{G(y, T(y), T(y))+G(y, y, y)\} \\
& =a G(y, T(y), T(y)),
\end{aligned}
$$

which is a contradiction.

Hence, if $y \neq T(y)$, then

$$
\inf [G(x, y, y)+G(x, T(x), T(x)): x \in X]>0 .
$$

Now applying Corollary 1 , we obtain a fixed point (say u) of $\mathrm{T}$.

The proof using (3.18) is similar. Uniqueness of $u$ and $G$-continuity of $T$ at $u$ are obtained by the same argument used above.

Received: May 2011. Revised: June 2012. 


\section{References}

[1] R.Chugh, T.Kadian, A.Rani, and B.E.Rhoades, "Property P in G-metric spaces," Fixed Point Theory and Applications, vol. 2010, Article ID 401684, 12 pages, 2010.

[2] B.C.Dhage, "Generalised metric spaces and mappings with fixed point," Bulletin of the Calcutta Mathematical Society, vol.84, no. 4, pp. 329-336, 1992.

[3] B.C.Dhage, "Generalised metric spaces and topological structure- I," Analele Stiintifice ale Universitătii "Al.I.Cuza" din Iasi. Serie Nouă. Matematică, vol.46, no. 1, pp. 3-24, 2000.

[4] S.Gähler, "2-metrische Räume und ihre topologische Struktur," Mathematische Nachrichten, vol.26, pp. 115-148, 1963.

[5] S.Gähler, "Zur geometric 2-metrische räume," Revue Roumaine de Mathématiques Pures et Appliquées, vol.40, pp. 664-669, 1966.

[6] K.S.Ha,Y.J.Cho, and A.White, "Strictly convex and strictly 2-convex 2-normed spaces," Mathematica Japonica, vol.33, no. 3, pp. 375-384, 1988.

[7] Osamu Kada, Tomonari Suzuki and Wataru Takahashi, "Nonconvex minimization theorems and fixed point theorems in complete metric spaces," Math. Japonica, vol.44, no. 2, pp. 381-391, 1996,.

[8] Sushanta Kumar Mohanta, "Property P of Ćirić operators in G-metric spaces," International J. of Math. Sci. and Engg. Appls., vol. 5, no. II, pp. 353-367, 2011.

[9] Z.Mustafa and B.Sims, "A new approach to generalized metric spaces," Journal of Nonlinear and convex Analysis, vol. 7, no. 2, pp. 289-297, 2006.

[10] Z.Mustafa and B.Sims, "Fixed point theorems for contractive mappings in complete G-metric spaces," Fixed Point Theory and Applications, vol. 2009, Article ID 917175, 10 pages, 2009.

[11] Z.Mustafa, H.Obiedat, and F. Awawdeh, "Some fixed point theorem for mapping on complete G-metric spaces," Fixed Point Theory and Applications, vol. 2008, Article ID 189870, 12 pages, 2008.

[12] Z.Mustafa, W.Shatanawi, and M.Bataineh, "Existence of fixed point results in G-metric spaces," International Journal of Mathematics and Mathematical Sciences, vol. 2009, Article ID 283028, 10 pages, 2009.

[13] Z.Mustafa and B.Sims, "Some remarks concerning D-metric spaces," in Proceedings of the International Conference on Fixed Point Theory and Applications, pp. 189-198, Valencia, Spain, July 2004.

[14] Z.Mustafa, A new structure for generalized metric spaces-with applications to fixed point theory, Ph.D. thesis, The University of Newcastle, Callaghan, Australia, 2005. 
[15] Z.Mustafa and H. Obiedat, "A fixed points theorem of Reich in G-metric spaces," Cubo A Mathematics Journal, vol. 12, no. 01, pp. 83-93, 2010.

[16] Z.Mustafa, F. Awawdeh and W.Shatanawi, "Fixed point theorem for expansive mappings in G-metric spaces," Int. J. Contemp. Math. Sciences, vol. 5, no. 50, pp. 2463-2472, 2010.

[17] S.V.R.Naidu, K.P.R.Rao, and N.Srinivasa Rao, "On the concept of balls in a D-metric space," International Journal of Mathematics and Mathematical Sciences, no. 1, pp. 133-141, 2005.

[18] W.Shatanawi,"Fixed point theory for contractive mappings satisfying $\phi$-maps in G-metric spaces," Fixed Point Theory and Applications, vol. 2010, Article ID 181650, 9 pages, 2010. 